\title{
Pancreatic Neuroendocrine Microadenoma
}

National Cancer Institute

\section{Source}

National Cancer Institute. Pancreatic Neuroendocrine Microadenoma. NCI Thesaurus.

Code C45834.

A well differentiated pancreatic neuroendocrine tumor which measures less than $0.5 \mathrm{~cm}$

in diameter and it is not associated with a hormonal syndrome. 